\title{
Formation of ultrathin Ni germanides: solid-phase reaction, morphology and texture
} K. van Stiphout, ${ }^{1}$ F.A. Geenen, ${ }^{2}$ B. De Schutter, ${ }^{2}$ N.M. Santos, ${ }^{1}$ S.M.C. Miranda, ${ }^{1}$ V. Joly, ${ }^{1}$ C. Detavernier, ${ }^{2}$ L.M.C. Pereira, ${ }^{1}$ K. Temst $^{1}$ and A. Vantomme ${ }^{1}$

1) KU Leuven, Instituut voor Kern- en Stralingsfysica, 3001 Leuven, Belgium

${ }^{2)}$ Ghent University, Department of Solid State Sciences, Krijgslaan 281/S1, 9000 Ghent, Belgium

The solid-phase reaction of ultrathin $(\leq 10 \mathrm{~nm})$ Ni films with different Ge substrates (single-crystalline (100), polycrystalline, and amorphous) was studied. As thickness goes down, thin film texture becomes a dominant factor in both the film's phase formation and morphological evolution. As a consequence, certain metastable microstructures are epitaxially stabilized on crystalline substrates, such as the $\epsilon-\mathrm{Ni}_{5} \mathrm{Ge}_{3}$ phase or a strained NiGe crystal structure on the single-crystalline substrates. Similarly, the destabilizing effect of axiotaxial texture on the film's morphology becomes more pronounced as film thicknesses become smaller. These effects are contrasted by the evolution of germanide films on amorphous substrates, on which neither epitaxy nor axiotaxy can form, i.e. none of the (de)stabilizing effects of texture are observed. The crystallization of such amorphous substrates however, drives the film breakup. 


\section{INTRODUCTION}

Thermal reactions of planar thin metal films (10 - $100 \mathrm{~nm})$ with elemental semiconductors ( $\mathrm{Si}, \mathrm{Ge}$ ) have been studied for several decades. As a model system for thin film growth, these reactions are often considered when studying the role of various aspects of thin film growth, such as stress, texture, addition of an alloying element... An important aspect of thin film growth is the influence of down-scaling: as film thickness is reduced to a few nm, the role of long-range diffusion diminishes, whereas the relative importance of interfaces and stress increases. As a result, the solid-phase reaction (SPR) of some silicide systems, such as $\mathrm{NiSi}_{2}{ }^{1}$ or $\mathrm{TiSi}_{2}{ }^{2}$, changes as film thickness is reduced: different reaction paths are found, including the stabilization of metastable phases, often in favor of those with epitaxial alignment. Along with scientific interest, such changes in SPR are technologically relevant due to the trend of aggressive down-scaling in CMOS technology.

Historically, research on thin and ultrathin $(<10 \mathrm{~nm})$ film reactions has mostly focused on reactions with $\mathrm{Si}$ and less on those with Ge. As Ge is considered a strong, alternative candidate to $\mathrm{Si}$ in state-of-the-art CMOS technology, ${ }^{3}$ renewed interest in thin metal film reactions with Ge has sparked a lot of research in recent years. ${ }^{4-9}$ Amongst many different metals, the reaction of thin Ni films with Ge has received significant attention. ${ }^{5-10}$ Overall, the reaction of thin nickel films $(\geq 10 \mathrm{~nm})$ begins upon deposition with the growth of a thin layer of the $\epsilon-\mathrm{Ni}_{5} \mathrm{Ge}_{3}$ phase at the interface, which thickens at the expense of pure $\mathrm{Ni}$ around $160^{\circ} \mathrm{C}$. This phase is later consumed by the NiGe phase, the final germanide to be formed. The growth conditions of the NiGe phase depend on the nature of the Ge substrate: when grown on single-crystal $\mathrm{Ge}(111)$, the NiGe phase grows only after the $\epsilon-\mathrm{Ni}_{5} \mathrm{Ge}_{3}$ phase has consumed all nickel, around $300^{\circ} \mathrm{C}$. On other substrates such as $\mathrm{Ge}(100)$, polycrystalline $\mathrm{Ge}$ (poly-Ge) and amorphous Ge (a-Ge) however, the NiGe phase grows simultaneously with the $\epsilon-\mathrm{Ni}_{5} \mathrm{Ge}_{3}$ phase, at the expense of the Ni layer. After depletion of all unreacted $\mathrm{Ni}$, the $\epsilon-\mathrm{Ni}_{5} \mathrm{Ge}_{3}$ phase is consumed by the NiGe phase until the reaction is complete. ${ }^{8}$

The germanide phases growing during the Ni-Ge reaction are known to be strongly textured on single-crystalline substrates: the film grains have a preferred alignment with respect to the substrate. ${ }^{5,8}$ The first phase to appear, the $\epsilon-\mathrm{Ni}_{5} \mathrm{Ge}_{3}$ phase, grows epitaxially on $\mathrm{Ge}(100)$ 
and Ge(111), in two twinning orientations (labeled A and B) which are related with one another through a rotation around the normal of the Ge $\{110\}$ planes as described by De Schutter et al. ${ }^{8}$ The NiGe phase is highly textured as well: several epitaxial alignments of NiGe grains were identified. ${ }^{5,8}$ In such epitaxial orientations, the planes of the film grains and those of the substrates match two-dimensionally at the interface. Additionally, some (weak) axiotaxial components were found in the texture of the NiGe phase: ${ }^{5}$ axiotaxy denotes the one-dimensional alignment of film planes with those of similar lattice spacing in the substrate across the interface, resulting in an off-normal fiber texture. Texture influences many thin film reactions and the morphological evolution of the resulting films, ${ }^{11,12}$ including the Ni-Ge system. The difference between the phase sequence on Ge(100) and on $\mathrm{Ge}(111)$ is often attributed to the $\epsilon-\mathrm{Ni}_{5} \mathrm{Ge}_{3}$ epitaxy, which has a smaller lattice mismatch with $\mathrm{Ge}(111)$ than with $\mathrm{Ge}(100)$, thus stabilizing the germanide through a lower interface energy. Additionally, axiotaxy, which is present in the NiGe texture, has been shown to facilitate agglomeration of thin films. ${ }^{12}$

Both the formation of a crystalline germanide upon deposition, as well as the simultaneous growth of two different germanide phases are unusual phenomena for thin film reactions. ${ }^{6}$ Moreover, the strong influence of texture on the SPR is likely even more pronounced when film thickness is decreased, as interfaces become more important. All of the above make the $\mathrm{Ni}-$ Ge reaction an interesting model system for solid-phase reactions in the ultrathin regime. In this paper, we report on the reaction of ultrathin $(\leq 10 \mathrm{~nm}) \mathrm{Ni}$ films with Ge. We focus on the phase sequence of germanides, their texture and the morphology of the film - as well as their mutual interplay. The reaction on three different substrates was investigated: Ge(100), poly-Ge and a-Ge. Despite similar reaction paths for thicker Ni films on these different substrates, ${ }^{5,13}$ our experiments show that for film thicknesses reduced to only a few nm, the stability of the crystalline phases and the film morphology are significantly influenced by the nature of the substrate.

\section{EXPERIMENTAL}

Films of 2 - $10 \mathrm{~nm}$ Ni were deposited by molecular beam epitaxy (MBE) on three different Ge substrates at room temperature: single-crystalline Ge(100), polycrystalline Ge (poly-Ge) 
and amorphous Ge (a-Ge). Prior to deposition, Ge(100) substrates were dipped in HF(2\%), blown dry with nitrogen and immediately loaded into ultra-high vacuum $\left(\leq 10^{-9} \mathrm{mbar}\right)$. Poly-Ge and a-Ge were prepared by depositing $100 \mathrm{~nm}$ of $\mathrm{Ge}$ onto a $\mathrm{SiO}_{2}$ substrate at room temperature. Before Ni deposition, the poly-Ge was annealed to $700^{\circ} \mathrm{C}$ in $\mathrm{UHV}$ to crystallize the Ge layer. Whereas the surface roughness (expressed as the standard deviation of the surface height) of the single-crystalline and amorphous Ge samples were estimated to be less than $0.2 \mathrm{~nm}$, the surface roughness of these polycrystalline Ge samples was estimated at $1.5 \mathrm{~nm} .{ }^{1}$ The crystallinity of the Ge surface (or lack thereof) was confirmed by reflection high-energy electron diffraction (RHEED) for all substrates.

The formation of crystalline phases on $\mathrm{Ge}(100)$ was monitored as the samples were annealed, using in situ X-ray diffraction (XRD) measurements at the X20C beamline of the National Synchrotron Light Source (NSLS) at Brookhaven National Laboratory. The wavelength used was $1.797 \AA$, the samples were kept in a high purity He flow during annealing at $1^{\circ} \mathrm{C} / \mathrm{s}$. The sample normal was misaligned by $4^{\circ}$ to the scattering plane, to avoid strong substrate peaks saturating the detector. Consequently, diffraction of strongly textured phases is significantly diminished. ${ }^{8}$ In situ XRD measurements on polycrystalline and amorphous Ge were carried out in a conventional, $\mathrm{CuK}_{\alpha}$ setup at the university of Gent, using a He + $5 \% \mathrm{H}_{2}$ mixture as ambient.

To fully indentify the crystalline phases and their texture, ex situ pole figures of quenched samples were measured at the DiffAbs beam line of Soleil using a wavelength of $1.540 \AA$. Diffraction was recorded by an X-ray pixel area detector (XPAD) allowing the fast acquisition and reconstruction of pole figures for a wide window of $2 \theta,{ }^{14}$ ranging from $26^{\circ}$ to $56^{\circ}$. During pole figure measurements, the samples were rotated $90^{\circ}$ around their normal ( $\phi$ rotation) and $90^{\circ}$ in the polar direction ( $\chi$ rotation), effectively probing one quarter of a pole figure (for a given $d$-spacing). Using the substrate's fourfold symmetry, the data were

\footnotetext{
${ }^{1}$ Although the STM measurement did not asses the surface roughness of the polycrystalline Ge directly, an estimate was made by comparing the roughness of the film at similar stages of the reaction on both single-crystalline and polycrystalline Ge, assuming the roughness of the film is identical, and that the difference in roughness is entirely due to substrate roughness.
} 
extended to full pole figures.

The sheet resistance of the samples during annealing was measured in situ by the fourpoint probe method, carried out in inert Ar ambient. Samples were annealed at $1^{\circ} \mathrm{C} / \mathrm{s}$. For measurements on single-crystalline $\mathrm{Ge}(100)$, germanium-on-insulator substrates were used. Due to the continuously changing thickness and morphology of the films throughout the in situ measurements, the results are presented as sheet resistance (in arbitrary units) rather than resistivity. For visual comparison, all sheet resistance measurements are scaled by an arbitrary factor such that their minimum values roughly coincide. Hence, no absolute values of sheet resistance or resistivity values are presented.

The thickness of the deposited Ni films was verified using Rutherford backscattering spectrometry (RBS), assuming the bulk density of Ni. However, due to the higher atomic weight of $\mathrm{Ge}$ than that of $\mathrm{Ni}$, the signals of the two elements overlap when $\mathrm{Ni}$ is deposited onto a Ge(100) substrate. To achieve a more accurate thickness, the same Ni layer was deposited onto a $\mathrm{SiO}_{2}$ wafer positioned next to the Ge substrates, avoiding signal overlap in the RBS spectra. In the case of a-Ge and poly-Ge, overlap of the two signals was avoided by using a beam energy of $2.7 \mathrm{MeV}$, separating the signal from the Ni layer and the $100 \mathrm{~nm}$ Ge layer.

The elemental composition of the first few $\mathrm{nm}$ at the surface of the samples was investigated by Auger electron spectroscopy (AES). Information on surface morphology was assessed by either scanning electron microscopy (SEM) or scanning tunneling microscopy $(\mathrm{STM})$.

\section{RESULTS}

The reaction of a $2 \mathrm{~nm} \mathrm{Ni}$ film $\left(18 \pm 2 \times 10^{15}\right.$ at $\left./ \mathrm{cm}^{2}\right)$ with the three different types of Ge substrates was recorded by in situ sheet resistance measurements and in situ XRD measurements. Figures 1, 2 and 3 show the reaction of a $2 \mathrm{~nm}$ Ni film with single-crystalline Ge(100), polycrystalline Ge and amorphous Ge, respectively. For all three substrates, the phase sequence is similar: the hexagonal $\epsilon-\mathrm{Ni}_{5} \mathrm{Ge}_{3}$ phase is formed first, followed by the growth of the NiGe phase. At higher temperatures, the germanide film breaks up. However, 


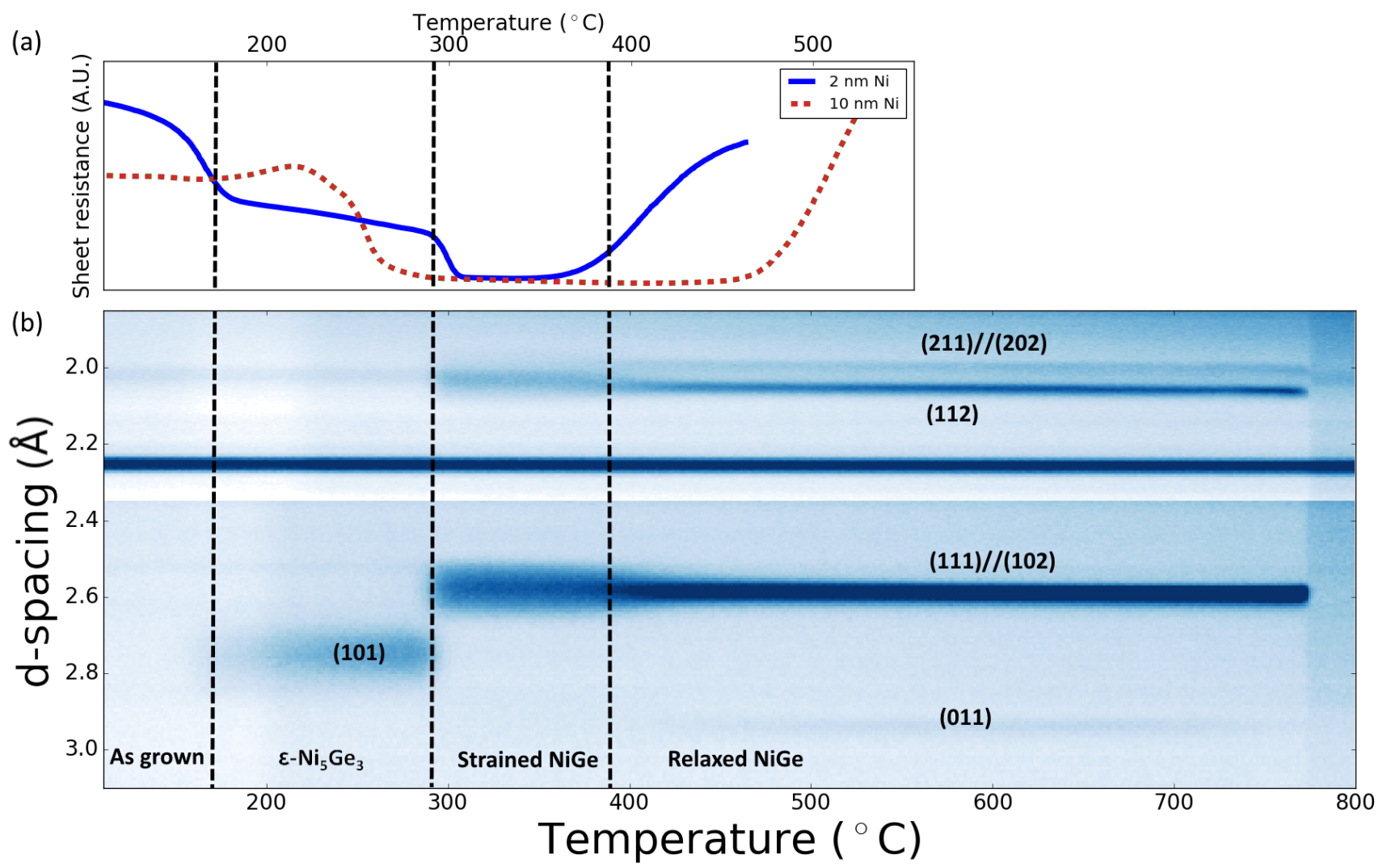

FIG. 1. The reaction of $2 \mathrm{~nm}$ Ni films with a $\mathrm{Ge}(100)$ substrate annealed at $1^{\circ} \mathrm{C} / \mathrm{s}$, recorded by (a) in situ sheet resistance and (b) in situ synchrotron XRD. In (a) a sheet resistance measurement of a $10 \mathrm{Ni}$ film is shown as well. Both sheet resistance measurements were normalized by their Ni thickness. The dashed, vertical lines indicate the different stages of the reaction. The peak around 2.25 Apresent throughout the anneal originates from the experimental setup, rather than the sample: it is not observed in other (ex situ) measurements.

the temperature at which the NiGe phase forms and at which the films break up, depends strongly on the nature of the substrate and film thickness. An overview of the formation and agglomeration/breakup temperatures of the NiGe phase is shown in Fig. 4. The morphological degradation of the films is also seen in the SEM images shown in Fig. 5 taken before and after film breakup. These results are elaborated upon below, for each substrate consecutively. 


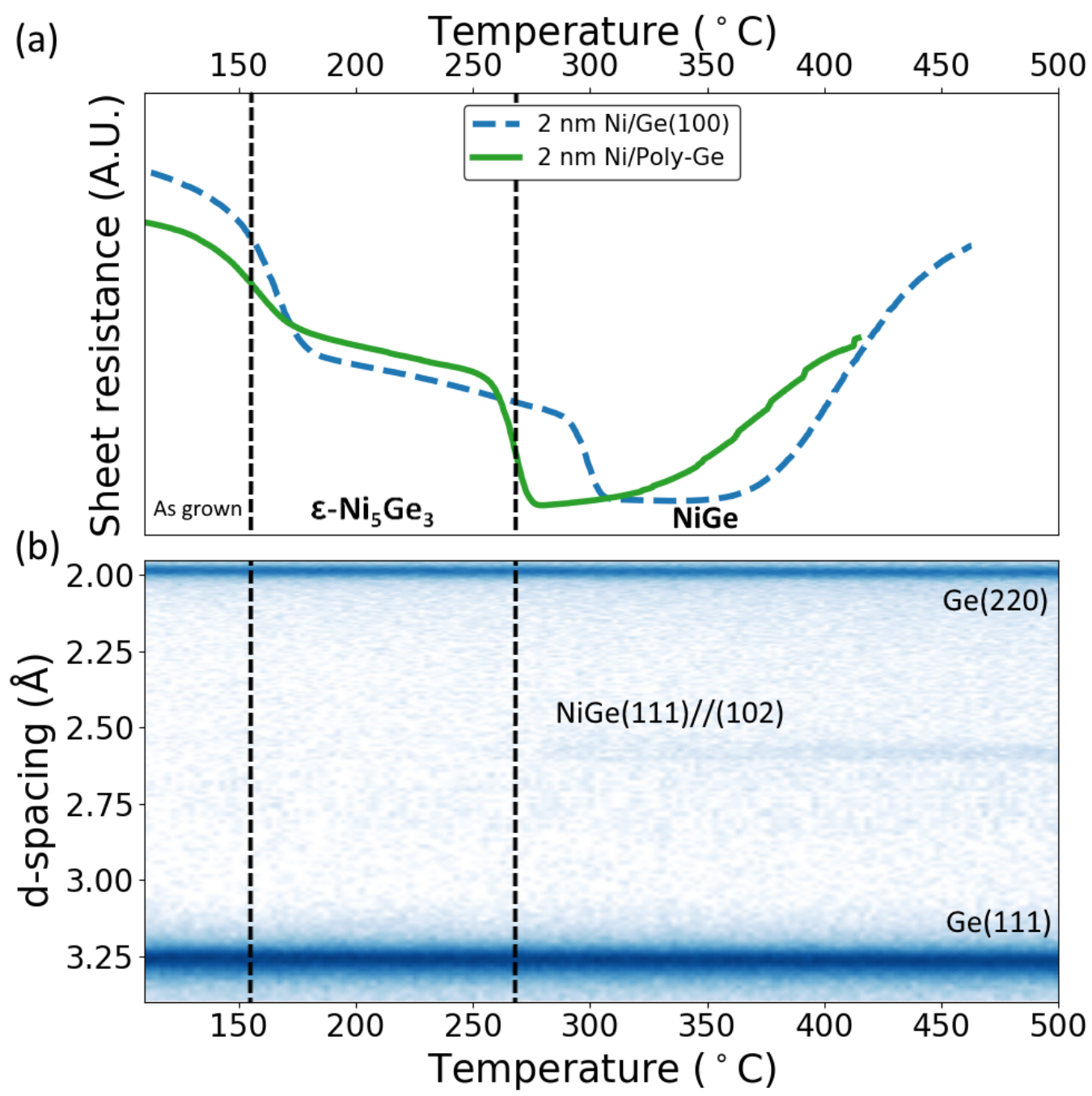

FIG. 2. The reaction of a $2 \mathrm{~nm}$ Ni film on polycrystalline Ge annealed at $1^{\circ} \mathrm{C} / \mathrm{s}$, recorded by (a) in situ sheet resistance and (b) in situ conventional XRD. In (a) the reaction on Ge(100) is reproduced from Fig. 1, showing a similar two-step reaction occurs on both substrates. The final phase, NiGe, is formed at around $270^{\circ} \mathrm{C}$, indicated by a drop in sheet resistance in (a) and a faint diffraction peak emerging in (b). The width of the diffraction peaks of the poly-Ge substrate remains constant throughout the reaction, suggesting no changes take place in the substrate. The dashed, vertical lines indicate the different stages of the reaction.

\section{A. Ultrathin $\mathrm{Ni}$ on $\mathrm{Ge}(100)$}

In figure 1(a) in situ sheet resistance measurements are shown for a 2 and $10 \mathrm{~nm} \mathrm{Ni}$ film on single-crystalline $\mathrm{Ge}(100)$. For the $10 \mathrm{~nm} \mathrm{Ni}$ film, the sheet resistance measurement is 


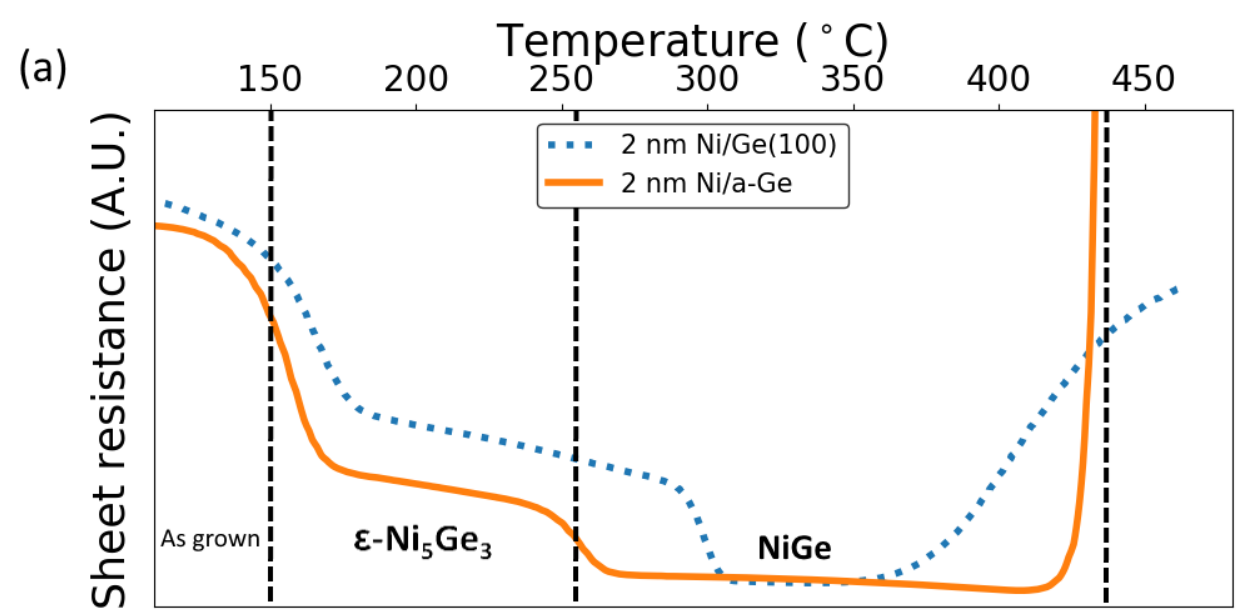

(b)

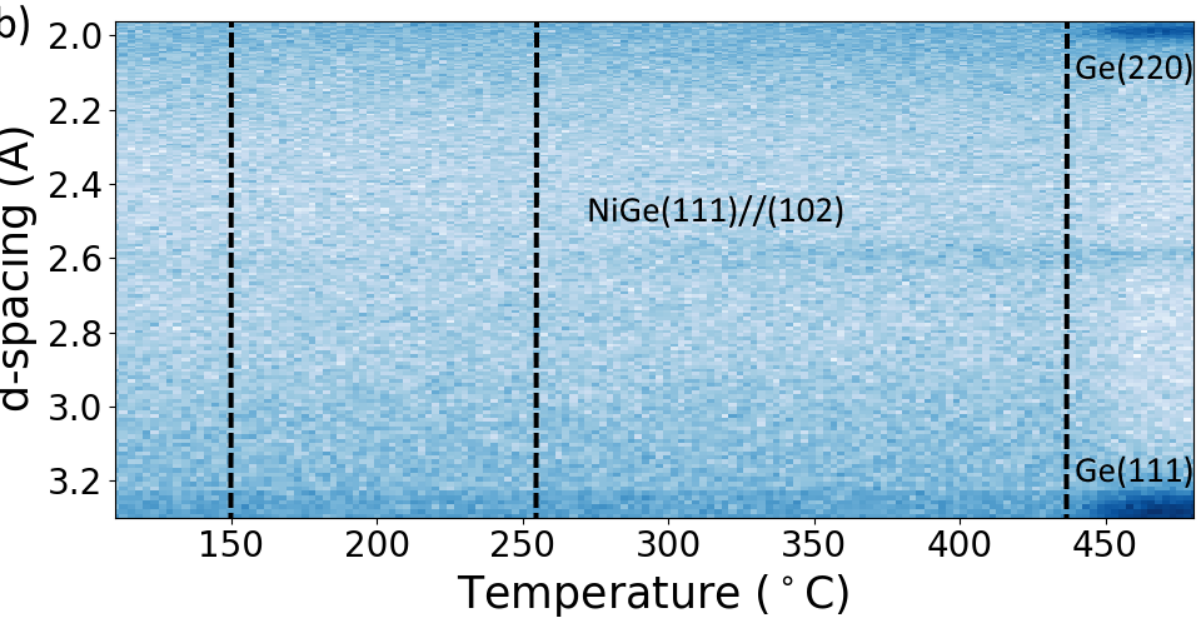

FIG. 3. The evolution of a $2 \mathrm{~nm}$ Ni film on amorphous $\mathrm{Ge}$ annealed at $1^{\circ} \mathrm{C} / \mathrm{s}$, recorded by (a) in situ sheet resistance and (b) in situ conventional XRD. In (a) the reaction on Ge(100) is reproduced from Fig. 1, showing a similar two-step reaction occurs on both substrates. At $440^{\circ} \mathrm{C}$, the sheet resistance rises abruptly, concurrent with the crystallization of the amorphous Ge, as evidenced by Ge diffraction peaks appearing at the same temperature. The dashed, vertical lines indicate the different stages of the reaction.

almost identical to those for thicker films, for which simultaneous growth of the $\epsilon-\mathrm{Ni}_{5} \mathrm{Ge}_{3}$ and NiGe phases was observed. The film is converted to the NiGe phase at around $260^{\circ} \mathrm{C}$. For thin Ni films deposited on Ge, it was reported that the $\epsilon-\mathrm{Ni}_{5} \mathrm{Ge}_{3}$ phase grew upon deposition, which is true for the ultrathin $(2 \mathrm{~nm})$ films as well (see below). The sheet resistance measurement for $2 \mathrm{~nm} \mathrm{Ni}$ films shows clear differences with the one for $10 \mathrm{~nm} \mathrm{Ni}$. Two separate drops in sheet resistance at 160 and $300^{\circ} \mathrm{C}$ can clearly be distinguished. The first 


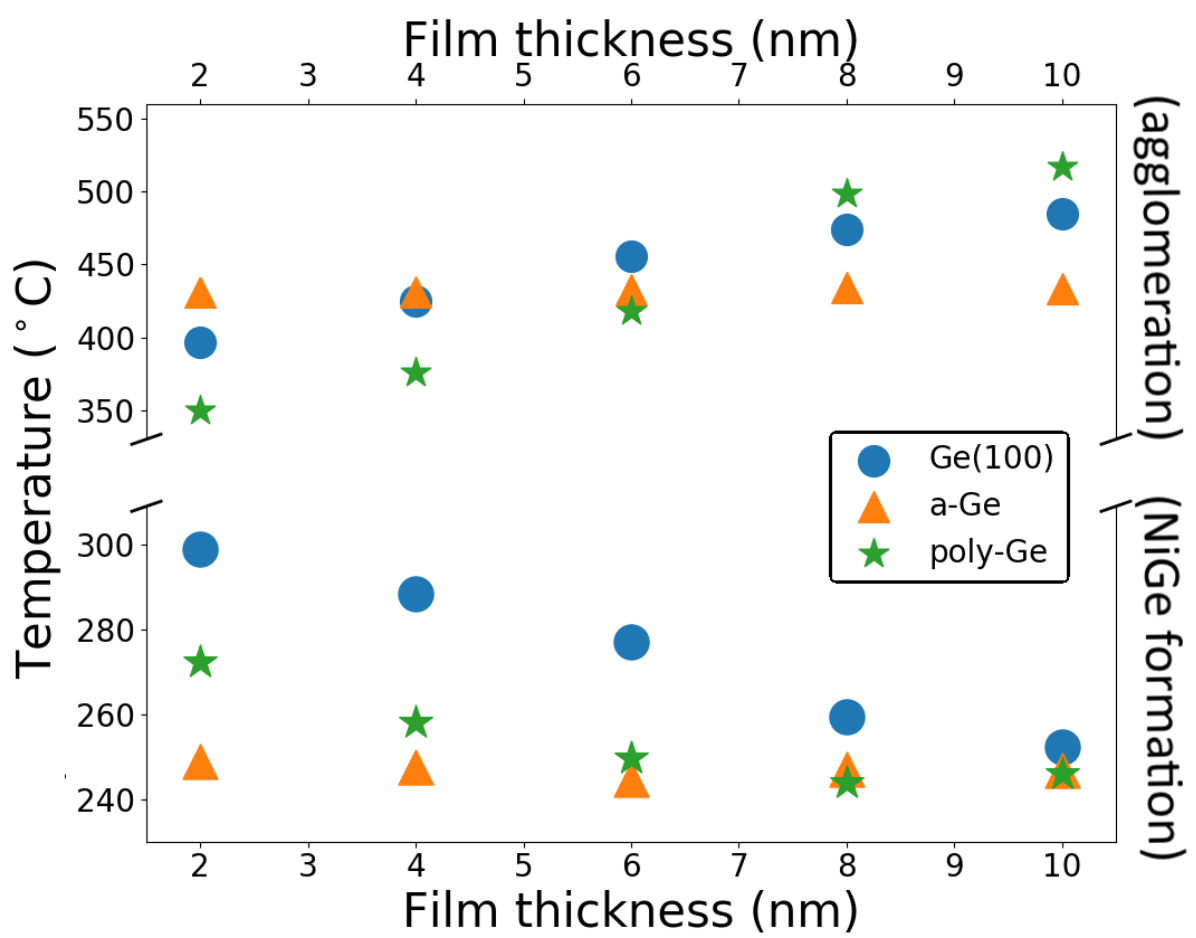

FIG. 4. NiGe formation (lower part) and agglomeration temperature (upper part) as function of initial Ni film thickness for different substrates, based on in situ sheet resistance measurements.

decrease corresponds with the further growth of the $\epsilon-\mathrm{Ni}_{5} \mathrm{Ge}_{3}$ phase. As confirmed by ex situ and in situ XRD (Fig. 1(b)), the $\epsilon-\mathrm{Ni}_{5} \mathrm{Ge}_{3}$ phase is the only crystalline phase detected in this temperature window and the intensity of its diffraction peaks increases with increasing temperature. At $300^{\circ} \mathrm{C}$, the NiGe phase is formed and the sheet resistance decreases again. No simultaneous growth of germanides is observed for the ultrathin film, in contrast to thicker films. Moreover, the temperature of the onset of NiGe growth is clearly higher for the $2 \mathrm{~nm}$ film than for the reaction of $10 \mathrm{~nm} \mathrm{Ni}$ (Fig. 4). NiGe growth is gradually delayed as films become thinner. The in situ XRD measurements shown in Fig. 1(b) and ex situ pole figures (see below) confirm this two-step reaction for films of $2 \mathrm{~nm} \mathrm{Ni}$ : diffraction peaks of the $\epsilon-\mathrm{Ni}_{5} \mathrm{Ge}_{3}$ phase and the $\mathrm{NiGe}$ are observed at 200 and $300^{\circ} \mathrm{C}$, respectively. Around $400^{\circ} \mathrm{C}$ however, the sheet resistance begins increasing and the diffraction peaks of the NiGe phase shift to lower angles, suggesting strain relaxation of the NiGe crystal. Based on $e x$ situ measurements, the lattice parameters of the strained NiGe crystal are $a=5.38 \AA, b=$ $3.41 \AA, c=5.89 \AA$ before relaxation (quenched at $350^{\circ} \mathrm{C}$ ), and $a=5.43 \AA, b=3.44 \AA, c=$ 

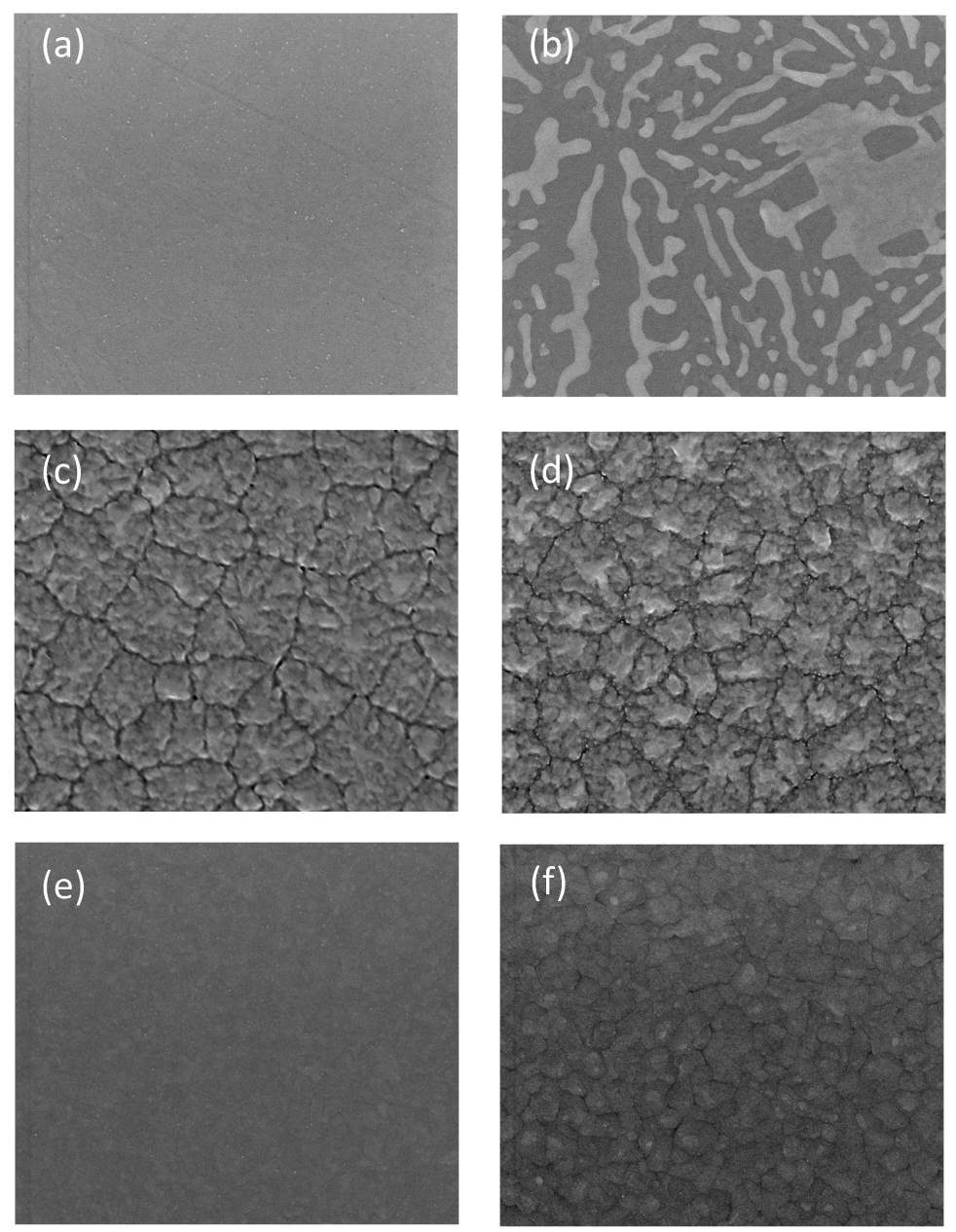

FIG. 5. $3 \times 3 \mu \mathrm{m}$ SEM images of the germanide films, before and after agglomeration/breakup, on Ge (100) (quenched at (a) $350^{\circ} \mathrm{C}$ and (b) $450^{\circ} \mathrm{C}$ ), polycrystalline Ge (quenched at (c) $300^{\circ} \mathrm{C}$ and (d) $350^{\circ} \mathrm{C}$ ) and amorphous Ge (quenched at (e) $350^{\circ} \mathrm{C}$ and (f) $450^{\circ} \mathrm{C}$ ). The as-deposited $\mathrm{Ni}$ films were $2 \mathrm{~nm}$ thick.

$5.84 \AA$ after relaxation (quenched at $450^{\circ} \mathrm{C}$ ), in correspondence with earlier reports of the NiGe structure..$^{15}$ NiGe is the last germanide formed, stable up to $780^{\circ} \mathrm{C}$, at which point it melts.

Ex situ pole figures of the $2 \mathrm{~nm} \mathrm{Ni}$ film on $\mathrm{Ge}(100)$ (Fig. 6), quenched at different stages of the reaction, allow both precisely determining the crystalline phases present in the film as well as identifying the film texture. At room temperature, diffraction of the epitaxial $\epsilon-\mathrm{Ni}_{5} \mathrm{Ge}_{3}$ phase is faintly seen, as mentioned above. The unusual growth of a germanide 
phase upon deposition has been reported previously for thicker films, ${ }^{8,16}$ and as with those thicker films, the $\epsilon-\mathrm{Ni}_{5} \mathrm{Ge}_{3}$ phase grows at room temperature in two different orientations, $\mathrm{A}$ and $\mathrm{B}$ (crystallographic twins, as described in the introduction). At $225^{\circ} \mathrm{C}$, the intensity of the $\epsilon-\mathrm{Ni}_{5} \mathrm{Ge}_{3}$ diffraction peaks has significantly increased, confirming further growth of the phase. The NiGe phase in samples quenched at $350^{\circ} \mathrm{C}$ exhibits a texture consisting mostly of epitaxial components, as described elsewhere. ${ }^{5,8}$ Axiotaxial lines of the NiGe(211) and NiGe(202) planes aligning with the Ge(220) planes are also present, yet only faintly. Annealing the film to temperatures higher than $400^{\circ} \mathrm{C}$ causes the NiGe structure to relax, which is also reflected in its texture: axiotaxial components become more intense after relaxation due to growth of axiotaxial grains. In terms of crystal alignment, the texture of these ultrathin films is identical to that of thicker NiGe films on Ge(100). ${ }^{5,8}$

The morphological stability of the germanide film is strongly correlated with the solidphase reaction described above. Initially, the $2 \mathrm{~nm} \mathrm{Ni}$ film's morphology is rough upon deposition, as confirmed by STM (not shown). This large roughness is probably due to a combination of the growth of the $\epsilon-\mathrm{Ni}_{5} \mathrm{Ge}_{3}$ phase at room temperature, and the VolmerWeber growth of very thin $\mathrm{Ni}$ layers on $\mathrm{Ge}(100) .{ }^{17}$ At around $160^{\circ} \mathrm{C}$, the film becomes flatter as the $\epsilon-\mathrm{Ni}_{5} \mathrm{Ge}_{3}$ phase continues to grow. Even as the film is converted to the NiGe phase, its morphology remains stable up to around $380^{\circ} \mathrm{C}$. Annealing to higher temperatures leads to a rougher, agglomerated surface: the degradation of the germanide film at these temperatures is shown in Figs. 5(a) and 5(b).

As expected, agglomeration sets in at lower temperatures for thinner NiGe films (Fig. 4). ${ }^{18}$ Moreover, for the thinnest Ni layer $(2 \mathrm{~nm})$, the increase in resistivity and the NiGe strain relaxation occur simultaneously. This is illustrated in Fig. 7(a): based on the in situ measurements in Figs. 1(a) and 1(b), a comparison is shown between the structural relaxation (represented by the NiGe(111) d-spacing) and the film's morphology (represented by the broadening of the $\mathrm{NiGe}(111)$ diffraction peak and the sheet resistance). The width of the diffraction peaks is inversely proportional to the film's (out-of-plane) grain size, ${ }^{2}$ and

\footnotetext{
${ }^{2}$ The grain sizes in the agglomerated film can be roughly estimated by the Scherrer equation: ${ }^{39}$ the column
} 
(a) $20^{\circ} \mathrm{C}$ $\varepsilon-\mathrm{Ni}_{5} \mathrm{Ge}_{3}(\mathrm{~A})$

(b) $250^{\circ} \mathrm{C}$

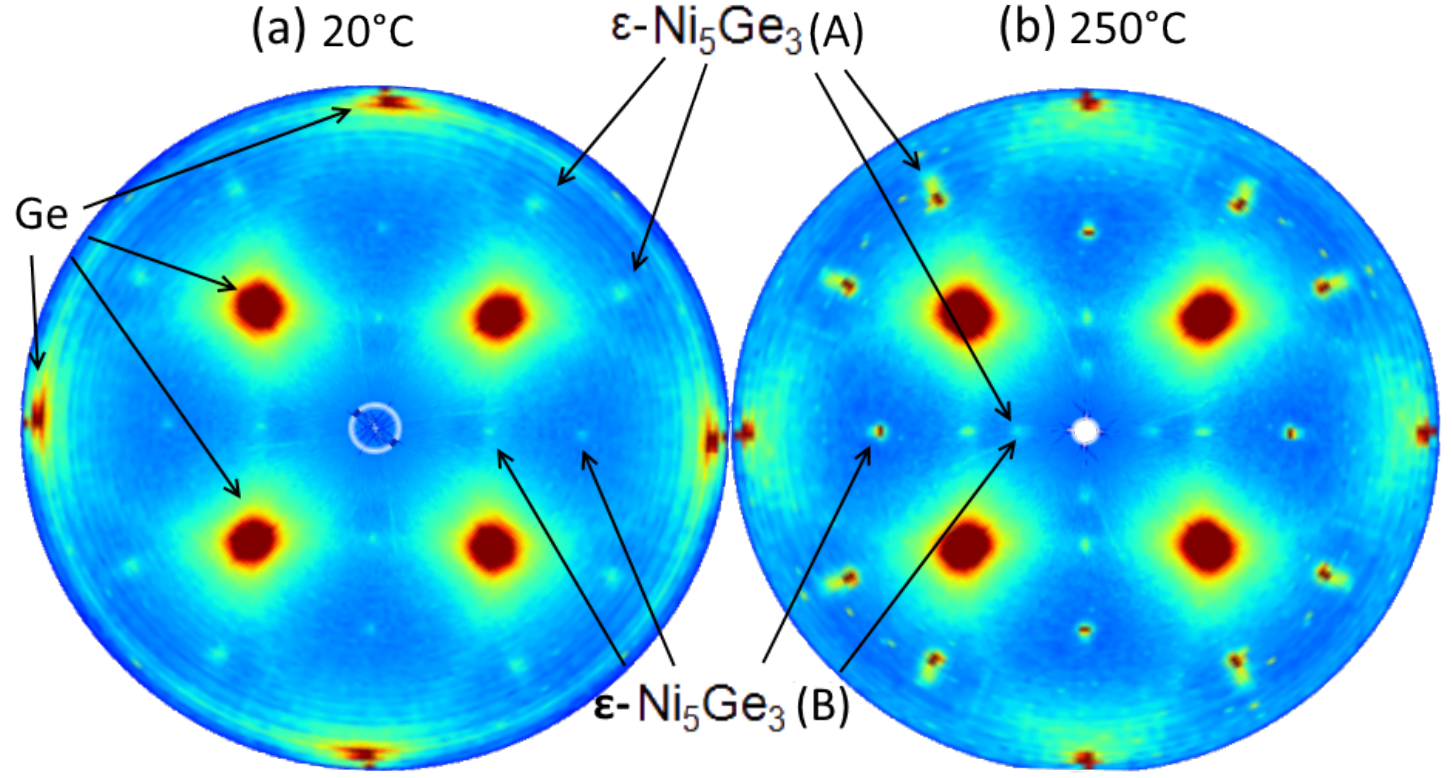

(c) $350^{\circ} \mathrm{C}$

(d) $450^{\circ} \mathrm{C}$

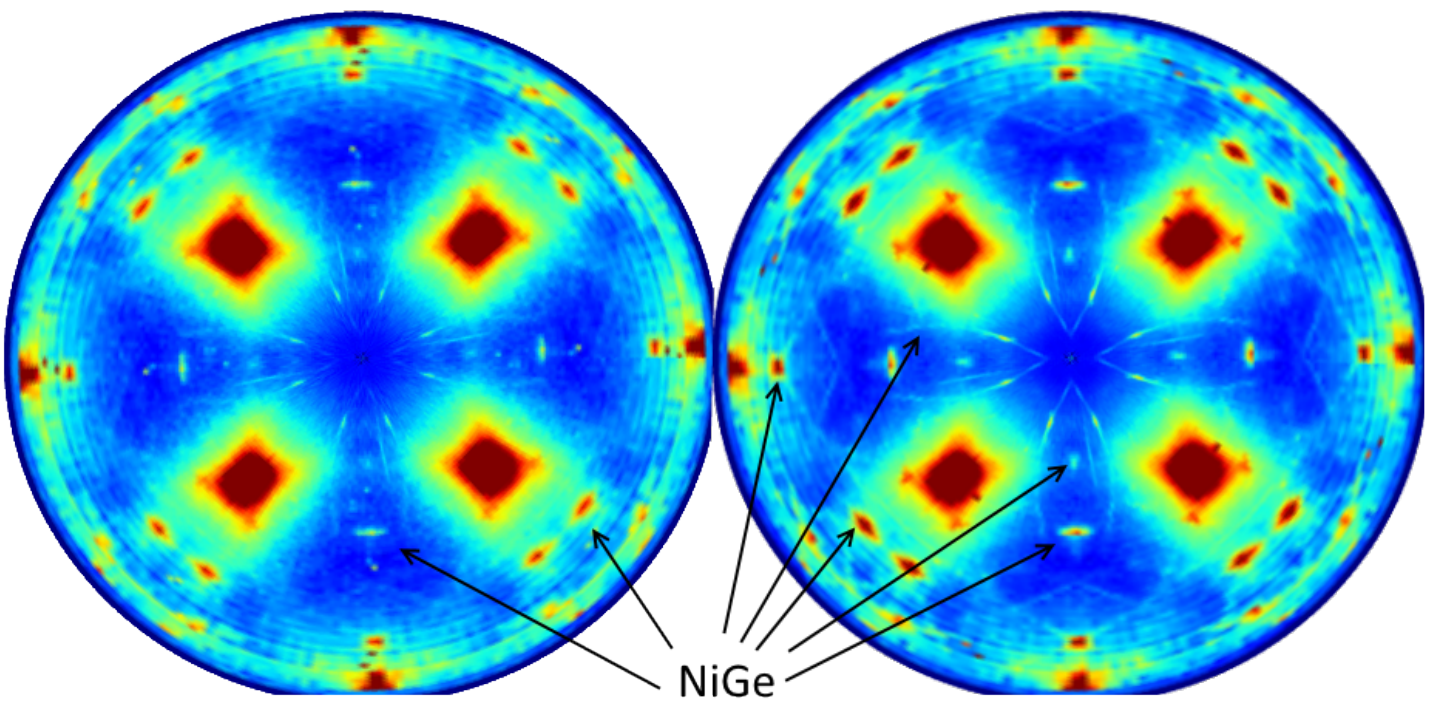

FIG. 6. Ex situ pole figures of a $2 \mathrm{~nm}$ Ni layer on Ge(100), quenched at (a) room temperature, (b) 225 , (c) 350 and (d) $450^{\circ} \mathrm{C}$. Pole figures (a) and (b) were taken at $2.056 \AA$, showing the (102) diffraction peaks of $\epsilon-\mathrm{Ni}_{5} \mathrm{Ge}_{3}$. Pole figures (c) and (d) were taken at $1.997 \AA$, showing diffraction of the (211)//(202) planes of NiGe. The color scale is identical for (a) and (b), and identical for (c) and (d). Ge(220) diffraction peaks are visible in all figures $(d$-spacing $=1.998 \AA)$.

height of the grains appears to be around $10 \mathrm{~nm}$, whereas a continuous, planar film for the same amount 


\section{B. Ultrathin $\mathrm{Ni}$ on poly-Ge}

On polycrystalline Ge, a similar two-step phase formation is observed as on Ge(100) (Fig. 2(a)). Around $170^{\circ} \mathrm{C}$, the sheet resistance drops due to the $\epsilon-\mathrm{Ni}_{5} \mathrm{Ge}_{3}$ phase growth. The growth of the NiGe phase is delayed to higher temperatures as the film thickness decreases $\left(270^{\circ} \mathrm{C}\right.$ for $\left.2 \mathrm{~nm} \mathrm{Ni}\right)$, although not as much as for single-crystalline Ge $\left(300^{\circ} \mathrm{C}\right)$ (Fig. 4). The delay of NiGe formation is confirmed by conventional in situ XRD for a $2 \mathrm{~nm} \mathrm{Ni}$ film (2(b)). In this measurement, two diffraction peaks originating from the polycrystalline Ge are seen throughout the reaction. Around $270^{\circ} \mathrm{C}$ however, a faint diffraction peak emerges, which can be attributed to the $\mathrm{NiGe}(111) / /(102)$ planes. Other diffraction peaks originating from either the NiGe phase or its preceding phases are not visible.

For a $2 \mathrm{~nm} \mathrm{Ni}$ film, agglomeration on polycrystalline Ge sets in only after the formation of the NiGe phase, similar to Ge(100). However, the $2 \mathrm{~nm}$ Ni film agglomeration occurs

of $\mathrm{Ni}$ is expected to have an average column height of $4 \mathrm{~nm}$. It is known that the actual sizes of grains can differ from those obtained using the Scherrer equation, ${ }^{39}$ and these values should not be taken too strictly. However, the obtained result - that the grains are larger than what is expected for a film which has not agglomerated - is in accordance with other observations, such as the increased surface roughness or sheet resistance. 
(a)

(b)
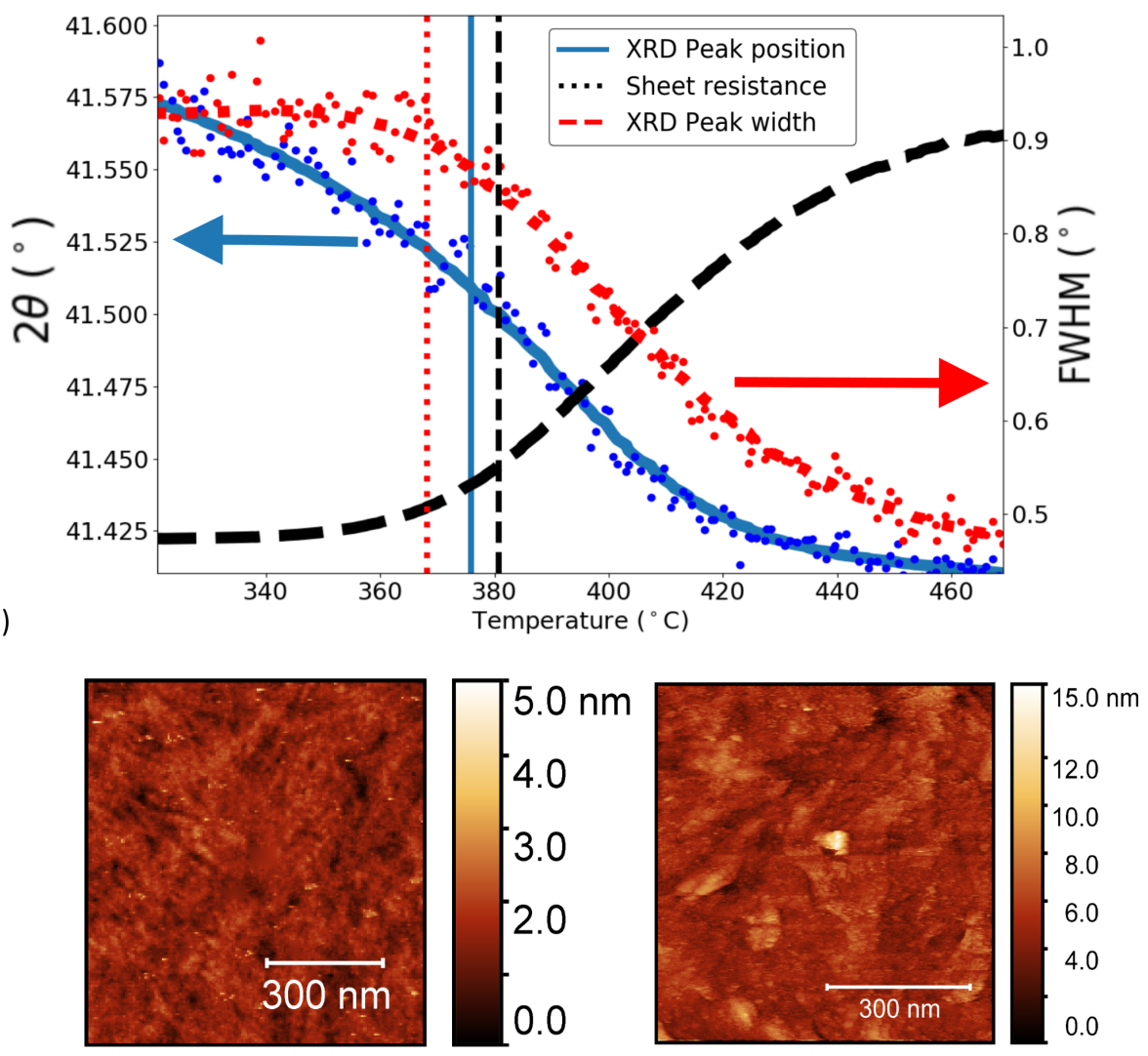

FIG. 7. (a) Temperature dependence of the NiGe(111) diffraction peak position and width (deduced from the in situ XRD measurement in Fig. 1(b)), and of the sheet resistance (Fig. 1(a))(no axis assigned) of a $2 \mathrm{~nm} \mathrm{Ni}$ film on $\mathrm{Ge}(100)$. The vertical lines indicate the minimum (maximum) of the second derivative of the (spline interpolated) curves, which all occur within a $15^{\circ} \mathrm{C}$ window. (b) STM images of the NiGe film, quenched at $350^{\circ} \mathrm{C}$ (left) and $450^{\circ} \mathrm{C}$ (right).

at lower temperatures than for single-crystalline Ge: at $350^{\circ} \mathrm{C}$, the germanide layer on polyGe has undergone significantly more roughening compared to those on single-crystalline Ge, as confirmed by sheet resistance, STM (not shown) and SEM (Figs. 5(c) and (d)). Remarkably, this behavior is opposite to that of thicker films: for films of $\geq 8 \mathrm{~nm} \mathrm{Ni}$, the films on polycrystalline Ge remain morphologically stable up to higher temperatures. This will be discussed below. It should also be noted that the increase of roughness is not due to grain growth in the polycrystalline substrate, i.e. the broadening of the polycrystalline Ge diffraction peaks remains unaltered, as confirmed by in situ (Fig. 2(b)) and ex situ XRD measurements. 


\section{Ultrathin $\mathrm{Ni}$ on a-Ge}

A sheet resistance measurement for the reaction of a $2 \mathrm{~nm}$ Ni film on amorphous Ge is shown in Fig. 3(a). Similar to the crystalline substrates, two steps can be seen in the sheet resistance indicating the formation of the hexagonal phase (confirmed by ex situ XRD, not shown) and the growth of the NiGe phase, respectively. The latter is also evidenced by a faint $\mathrm{NiGe}(111)$ diffraction peak emerging at the same temperature in the conventional in situ XRD measurement (Fig. 3(b)). Unlike the crystalline substrates however, no delay in NiGe formation is seen as the film thickness decreases (Fig. 4), the NiGe phase is seen forming around $250^{\circ} \mathrm{C}$, even for the thinnest films.

The morphological stability of the germanide film on a-Ge is different from that on crystalline Ge as well. No increase in sheet resistance is seen up to $440^{\circ} \mathrm{C}$, suggesting the film does not undergo significant agglomeration up to this temperature. $2 \mathrm{~nm} \mathrm{Ni}$ films on crystalline substrates however, are agglomerated at $400^{\circ} \mathrm{C}$. The stronger morphological stability of films on amorphous Ge is also confirmed by SEM measurements (figure 5(e)) and STM measurements (not shown): for a sample quenched at $350^{\circ} \mathrm{C}$, the germanide film's surface roughness on amorphous $\mathrm{Ge}$ is lower than any NiGe film on a crystalline substrate. At $440^{\circ} \mathrm{C}$ however, the sheet resistance abruptly increases at a rate much higher than on crystalline substrates. Moreover, conventional in situ XRD (Fig. 3(b)) reveals that this sudden increase of sheet resistance is concurrent with the crystallization of amorphous $\mathrm{Ge}$ at $440^{\circ} \mathrm{C}$. In SEM measurements of samples quenched at $450^{\circ} \mathrm{C}$ (Fig. 5(f)), the (poly)crystalline Ge grains are visible, similar to SEM images of the polycrystalline substrates in Figs. 5(c) and $5(\mathrm{~d})$.

AES measurements (Fig. 8(a)), probing the first few nm at the surface of the sample, no longer show a Ni signal for samples quenched at $450^{\circ} \mathrm{C}$, suggesting no NiGe film is present anymore at the surface. RBS measurements, performed on this sample, confirm nearly all 
Ni has diffused deeper into the Ge (Fig. 8(b)). Such behavior has also been reported for other systems undergoing metal-induced crystallization (MIC), as will be discussed below. Moreover, this phenomenon is not limited to the ultrathin regime: even for $10 \mathrm{~nm}$ films, the film breaks up upon crystallization of the underlying amorphous Ge, raising the sheet resistance by almost an order of magnitude, as can be seen in Fig. 9. Only for $15 \mathrm{~nm} \mathrm{Ni}$ films on amorphous Ge does the sheet resistance remain comparable to the previous stages of the reaction after crystallization. This suggests a continuous germanide film remains present at the surface, which only agglomerates at around $550^{\circ} \mathrm{C}$. However, the crystallization of the underlying amorphous Ge still increases the sheet resistance abruptly for these thicknesses. This is likely due to a significant part of the Ni atoms diffusing deeper in the substrate, resulting in a thinner film at the surface.

\section{DISCUSSION}

Reducing the Ni film thickness clearly has a strong influence on the film reaction with different types of Ge substrate. The film evolution, both in terms of crystallography and morphology, is intrinsically interwoven with its interfaces and stresses due to germanide formation. A schematic summary of the Ni-Ge reaction on the different substrates is shown in Fig. 10. Below, we first discuss the phase formation, then the morphological evolution of the films on different substrates.

\section{A. Solid-phase reaction}

The influence of reducing the film thickness $(<10 \mathrm{~nm})$ on the phase sequence of Ni films on $\mathrm{Ge}(100)$ or polycrystalline Ge has been shown above: as the film thickness decreases, the temperature at which the film is converted to the NiGe phase increases (Fig. 4). On amorphous Ge however, no such delay is observed.

As mentioned in the introduction, the reactions of thin $\mathrm{Ni}$ films (between 100 and 10 nm) with Ge(100), polycrystalline Ge or amorphous Ge are unconventional due to the simultaneous growth of two germanide phases during annealing, while unreacted $\mathrm{Ni}$ is still present. ${ }^{5,8,13}$ Typically, phases in thin film reactions grow sequentially as explained by the kinetic growth model by Gösele and $\mathrm{Tu}:{ }^{19}$ by introducing interface reaction barriers, it 

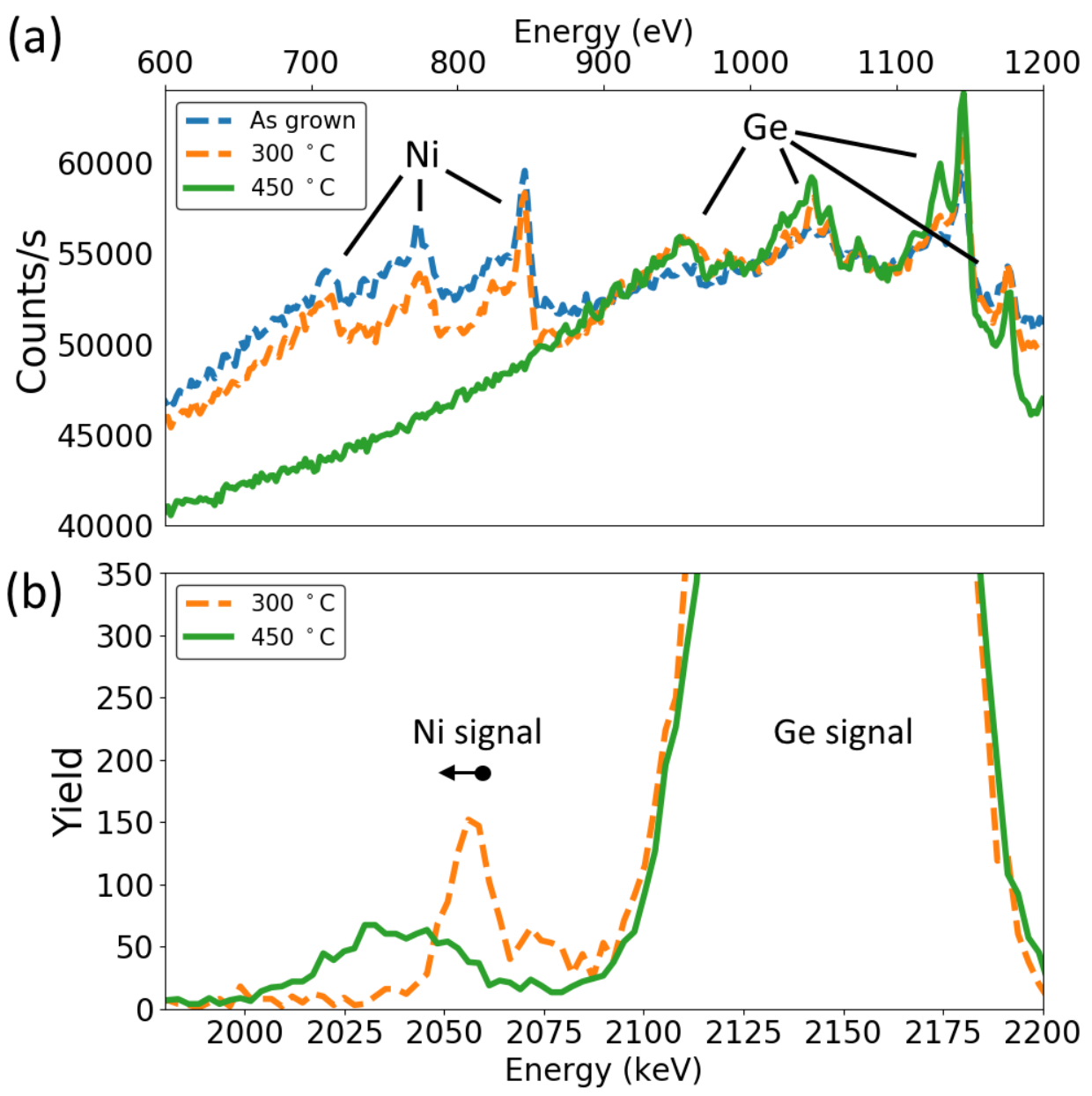

FIG. 8. Evidence of the NiGe film breaking up during crystallization of the amorphous Ge substrate. (a) AES spectra of a $2 \mathrm{~nm}$ Ni film on amorphous Ge annealed to different temperatures. No Ni signal was detected at the surface after crystallization of the Ge. (b) RBS spectrum of 2 nm Ni film on $100 \mathrm{~nm}$ amorphous Ge, before and after crystallization. Ni, initially confined to the surface, diffuses deeper into the Ge upon MIC.

predicts simultaneous growth of different phases only when a certain "critical thickness" is reached. In this context, the critical thickness of the $\epsilon-\mathrm{Ni}_{5} \mathrm{Ge}_{3}$ phase was said to be small, roughly estimated around $20 \mathrm{~nm} .^{7}$ However, this kinetic model cannot account for the delay of the NiGe formation: when film thicknesses go down, the model predicts the NiGe phase to grow at lower temperatures. Our experiments show that the opposite occurs.

Epitaxial stabilization of $\epsilon-\mathrm{Ni}_{5} \mathrm{Ge}_{3}$ offers a plausible explanation to the delay of $\mathrm{NiGe}$ 


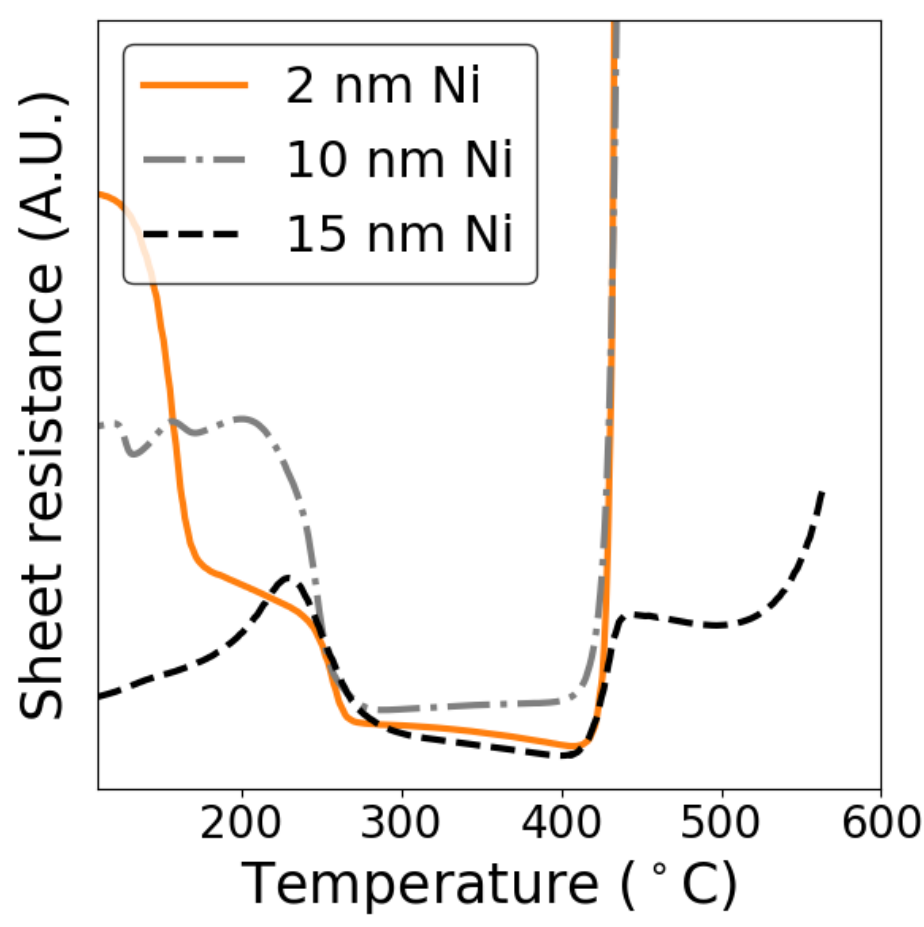

FIG. 9. Sheet resistance measurements for Ni films deposited on amorphous Ge, with different thicknesses. For films grown from $\leq 10 \mathrm{~nm} \mathrm{Ni}$, the sheet resistance increases abruptly upon crystallization of the Ge. For samples with a larger initial thickness $(\geq 15 \mathrm{~nm} \mathrm{Ni}$ ), the sheet resistance increases as well upon the substrate's crystallization, yet remains within the same order of magnitude. For such thick films, a gradual increase in sheet resistance is seen around $550^{\circ} \mathrm{C}$, as the germanide film begins to agglomerate.

formation on crystalline Ge substrates. As shown in Fig. 6, the $\epsilon-\mathrm{Ni}_{5} \mathrm{Ge}_{3}$ phase grows epitaxially on $\mathrm{Ge}(100)$. It has been shown that such strong epitaxial alignment can extend the temperature window in which an intermediate phase exists. ${ }^{20}$ Converting the $\epsilon-\mathrm{Ni}_{5} \mathrm{Ge}_{3}$ film to a NiGe film requires breaking the (low energy) epitaxial interface of the former, which is energetically disadvantageous. Consequently, the driving force for this conversion is lower than that for a $\epsilon-\mathrm{Ni}_{5} \mathrm{Ge}_{3}$ film with a more disordered interface (higher energy), and the growth of the NiGe phase is shifted to higher temperatures. Indeed, the strong discrepancy in growth kinetics between (thicker) Ni films on Ge(100) and on Ge(111) has been attributed to stronger $\epsilon-\mathrm{Ni}_{5} \mathrm{Ge}_{3}$ epitaxial alignment on $\mathrm{Ge}(111)$, resulting in a much larger temperature window for which this phase is present. ${ }^{8}$ This effect is most pronounced 


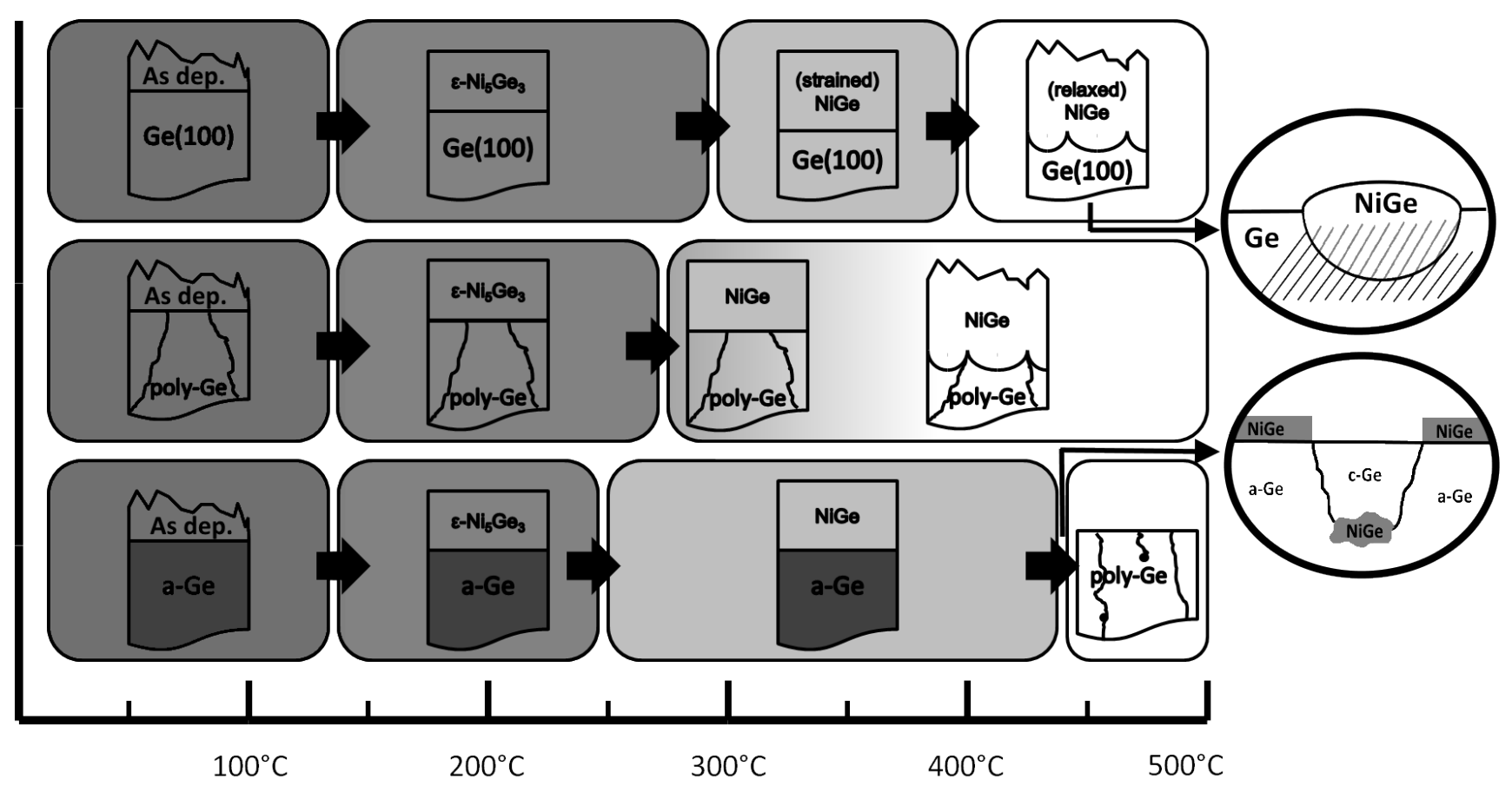

FIG. 10. Schematic overview of the reaction of a $2 \mathrm{~nm}$ Ni film deposited on three different substrates, as described in the results section. Whereas all films are initially equally far from stability (grey), they reach thermal equilibrium (white) at different temperatures.

for the thinnest films (Fig. 4), since the energy cost (interfacial area) over energy gain (grain volume) of converting to the new phase is higher than for thicker films. Hence, the conversion is delayed to higher temperatures.

A similar phenomenon occurs on polycrystalline Ge, where NiGe growth is delayed to higher temperatures due to the low-energy epitaxial interfaces between the $\epsilon-\mathrm{Ni}_{5} \mathrm{Ge}_{3}$ phase and Ge, be it to a lesser extent than on single crystal Ge(100). However, as thin film texture often strongly depends on substrate orientation ${ }^{8,20-22}$ and as low-energy interfaces do not always form on every grain orientation, one might rightfully question whether the hexagonal phase forms such periodic interfaces with a substrate in which virtually all orientations are present. Nevertheless, epitaxial stabilization might occur on poly-Ge due to the nature of the $\epsilon-\mathrm{Ni}_{5} \mathrm{Ge}_{3}$ texture: as pointed out by De Schutter et al. ${ }^{23,24}$ both texture components (A and $\mathrm{B}$ ) of the $\epsilon-\mathrm{Ni}_{5} \mathrm{Ge}_{3}$ phase exhibit 'double-alignment' epitaxy. Such epitaxies are characterized by an alignment of two or more planes across the interface, and are predicted to be 
unaffected by any substrate rotation or roughness. This is experimentally corroborated by reports of strong $\epsilon-\mathrm{Ni}_{5} \mathrm{Ge}_{3}$ epitaxy on single-crystal Ge substrates of different orientations: (100),(111) and (110). ${ }^{5,9}$ Hence, a grain of hexagonal germanide can likely form a low-energy interface with its underlying Ge grain, regardless of the orientation of the latter. Despite similar epitaxial stabilization however, NiGe nucleation occurs at lower temperatures on poly-Ge than for similar Ni thicknesses on Ge(100). This is due to the Ge grain boundaries present in the substrate: these boundaries increase the amount of triple and quadruple boundary junctions, which are well-known to facilitate nucleation. ${ }^{20}$

On amorphous Ge, the situation is different: the $\epsilon-\mathrm{Ni}_{5} \mathrm{Ge}_{3}$ phase cannot - by definition - have any epitaxial relationships with the substrate. Consequently, the first germanide phase is no longer epitaxially stabilized, hence no delay in NiGe nucleation is observed as film thickness goes down.

\section{B. Morphological evolution}

In general, thin films tend to break up into isolated islands at high temperatures, maximizing the volume-to-surface ratio. Models of thin film agglomeration ${ }^{18,25}$ predict that films are more prone to such roughening with decreasing thickness, as experimentally confirmed. ${ }^{26}$ In our experiments with Ni films on crystalline substrates, this was the case as well, as seen in Fig. 4. For $\leq 10 \mathrm{~nm}$ Ni films on amorphous substrates however, the breakup temperature was insensitive to the film thickness.

As was the case for the phase sequence, the nature of the interface has a large impact on the morphological stability on the film. Three different behaviors of film breakup were observed for the three different substrates studied, particularly between the crystalline substrates on the one hand, and the amorphous substrate on the other hand. The morphological stability of the films on crystalline substrates ( $\mathrm{Ge}(100)$ and poly-Ge) is discussed first. Afterwards, the mechanisms of NiGe film breakup on a-Ge are explained. 


\section{Agglomeration on Ge(100) and poly-Ge}

Initially, the film on $\mathrm{Ge}(100)$ remains morphologically stable even after conversion to the NiGe phase. At temperatures higher than $400^{\circ} \mathrm{C}$, the film morphology degrades, resulting in larger grain sizes, large surface roughness and high sheet resistance. This roughening is influenced by an interplay of two factors: the texture of the NiGe film and stress relaxation. On poly-Ge, agglomeration sets in earlier, due to a different texture of the NiGe film. Both agglomeration behaviors are discussed below.

On Ge(100), the film's morphological stability up to $400^{\circ} \mathrm{C}$ is due to the texture of the different germanide phases formed. As pointed out above, the $\epsilon-\mathrm{Ni}_{5} \mathrm{Ge}_{3}$ phase is strongly epitaxially aligned with the substrate, and the NiGe phase initially nucleates with strong epitaxial components in its texture (and only faint axiotaxy features) as well. Epitaxy is known to suppress agglomeration, ${ }^{27}$ such as for an epitaxial NiSi film on $\mathrm{Si}(100) .{ }^{28}$ However, unlike the well-known case of morphological stability of ultrathin Ni silicide films, ${ }^{1}$ the $\mathrm{Ni}$ germanide film does agglomerate.

The cause of morphological degradation is in part due to the stresses the film experiences, which results in strained NiGe crystalline structure. ${ }^{29}$ Three different origins of such stresses can be identified: thermal stress, resulting from a difference in thermal expansion between the film and the substrate; intrinsic stress, arising from volume changes during phase formation; epitaxial stress, caused by a lattice mismatch between the film and the substrate. ${ }^{30}$ For the formation of the NiGe phase (which has strong epitaxial components), all three types of stresses likely play a role in straining its crystalline structure.

As mentioned above, the crystal structure of the NiGe phase is compressively strained upon nucleation around $300^{\circ} \mathrm{C}$ and remains so for a temperature window of approximately $100^{\circ} \mathrm{C}$. As a result, the unit cell volume is decreased by $0.8 \%$, based on the diffraction peaks measured at room temperature after quenching from high temperature. Thermal stress likely does not play a big role in straining the film: its effect is estimated in the order of $0.2 \%$. Moreover, if thermal stress was the dominant origin, the residual strain at room temperature would be tensile, not compressive, due to the higher thermal (volumetric) 
expansion coefficients of the NiGe lattice than those of Ge. ${ }^{31}$ Hence, the strained state of the NiGe film upon its formation must mostly be due to a combination of intrinsic and epitaxial stress. Although the interplay between these two stresses is not entirely understood, it has been shown that epitaxial texture can slow down relaxation of intrinsic stress in films grown by solid-state reaction. ${ }^{29}$ Moreover, models for both intrinsic stress relaxation ${ }^{32}$ and epitaxial stress relaxation ${ }^{33}$ predict that relaxation becomes more difficult as the layer thickness decreases. Hence, strain relaxation - a thermally activated process - of ultrathin NiGe films is delayed to higher temperatures compared to their thicker counterparts. This stress relaxation has a profound effect on the morphology of the ultrathin films: relaxation is concurrent with an initial roughening of the film (Fig. 7). This is no coincidence: one proposed thin film relaxation mechanism is based on the roughening of the film, regardless of whether the origin of such stress is epitaxial ${ }^{33}$ or intrinsic ${ }^{29}$. This mechanism causes the NiGe film to roughen as it relaxes (Fig. 7), despite the epitaxial components in its texture.

At temperatures above $400^{\circ} \mathrm{C}$, the film has relaxed, yet it continues to agglomerate. Contrary to the situation before relaxation, the texture of the NiGe film plays a destabilizing role: axiotaxial components become significantly more intense at higher temperatures. The relationship between this type of texture and agglomeration is well-established:12,26,34 axiotaxy provides low-energy interfaces whose atomic arrangement across the interface are relatively independent of interface curvature, which facilitates agglomeration. For NiGe films on $\mathrm{Ge}(100)$, the film breakup is indeed driven by its axiotaxial components, once the crystal structure has relaxed. However, it is initially not clear why these grains grow only after relaxation, despite being (faintly) present in the texture of the NiGe phase upon its formation. This might be due to the strained NiGe crystal structure: as pointed out by Detavernier et al., ${ }^{12}$ the periodic matching of planes at the interface is independent of interface curvature only if the d-spaces are (nearly) identical, and the planes consequently align across the interface. If the projected d-spacings at the interface are not identical, film planes can be tilted over a small angle to compensate this difference. Maintaining periodicity at the interface is very sensitive to this tilt angle, and consequently, the lattice mismatch. Moreover, these authors showed that the intensity of axiotaxial components can be changed by altering the lattice spacing of the relevant crystal planes. ${ }^{12}$ Therefore, it should come as no surprise that a change in crystal lattice parameters (due to compressive stress) influences 
the film's texture.

Ex situ synchrotron diffraction experiments, revealed that the (211) $d$-spacing of a NiGe film (grown from $2 \mathrm{~nm} \mathrm{Ni}$ ) quenched at $450^{\circ} \mathrm{C}$ is $1.995 \pm 0.002 \AA$, corresponding within error to the $d$-spacing found for thicker $(\geq 30 \mathrm{~nm})$ films. ${ }^{5}$ At $450^{\circ} \mathrm{C}$, the film is fully relaxed. This value is very close to that of the $\mathrm{Ge}(220) d$-spacing $(1.998 \AA)$, the substrate planes with which the axiotaxial grains align. Consequently, such axiotaxial grains in the relaxed NiGe film can grow easily, agglomerating the film, as experimentally shown in our experiments. Before relaxation however, the situation is different: for $\mathrm{NiGe}$ films quenched at $350^{\circ} \mathrm{C}$, the $\mathrm{NiGe}(211) d$-spacing was $1.986 \pm 0.002 \AA$. As a result, the $\mathrm{NiGe}(211)$ planes have a larger lattice mismatch with $\mathrm{Ge}(220)$ than for the sample quenched at $450^{\circ} \mathrm{C}$. This larger mismatch makes the periodic matching of planes less robust against interface roughness, preventing the axiotaxial grains from growing easily and agglomerating the film before relaxation. A similar situation is found for the $\mathrm{NiGe}(202)$ planes, which also display axiotaxial alignment. It should be noted that the difference in lattice mismatch before and after relaxation is relatively small (around $0.5 \%$ ) and that thermal stress is not taken into account. Nevertheless, the model of plane alignment across the interface provides a qualitative argument as to why axiotaxy destabilizes the film's morphology only after relaxation: as long as the crystal structure remains strained, axiotaxial interfaces are not robust against roughening and agglomeration is temporarily prevented.

The morphological evolution of ultrathin Ni films on polycrystalline Ge is somewhat comparable with that on $\mathrm{Ge}(100)$ : the film stays morphologically stable during the $\epsilon-\mathrm{Ni}_{5} \mathrm{Ge}_{3}$ phase and agglomerates after forming the NiGe phase. Unlike on single-crystalline Ge however, no significant temperature window of morphological stability is seen and agglomeration of the film begins almost right after NiGe formation i.e. at a much lower temperature than for $\mathrm{Ge}(100)$ for the thinnest films. In contrast, this difference of agglomeration temperature is far less pronounced for thicker Ni films (Fig. 4). In fact, the figure suggests that thin NiGe films (grown from $\geq 8 \mathrm{~nm}$ Ni layers) on single-crystalline Ge agglomerate at slightly lower temperatures than those on polycrystalline Ge, similar to the (exceptional) case of NiSi films on Si substrates. ${ }^{26}$ 
A possible explanation for this specific behavior is the lack of epitaxy that can form on polycrystalline Ge. Unlike the $\epsilon-\mathrm{Ni}_{5} \mathrm{Ge}_{3}$ phase, the NiGe phase likely cannot form any lowenergy epitaxial interfaces on the polycrystalline Ge grains, as all the epitaxial components exhibit 'aligned' or 'matched' epitaxy. ${ }^{23}$ Hence, for $2 \mathrm{~nm}$ Ni films the film morphology on polycrystalline Ge is not stabilized by NiGe epitaxy as it was on Ge(100) and agglomeration sets in at lower temperatures on the former. When the film thickness is increased however, the temperature window of epitaxial, morphological stability on Ge(100) is diminished. The thicker NiGe film relaxes readily upon formation, ${ }^{8}$ and the agglomeration of the axiotaxial components is no longer suppressed. Hence, for thicker films $(\geq 8 \mathrm{~nm} \mathrm{Ni})$, the agglomeration temperatures of $\mathrm{Ge}(100)$ and polycrystalline Ge switch over. The stronger axiotaxial components of the film on the single-crystalline substrates cause the film to agglomerate first. However, it should be noted that these arguments concerning the 'texture' of the $\epsilon-\mathrm{Ni}_{5} \mathrm{Ge}_{3}$ or NiGe film on polycrystalline Ge are inferred from theoretical models ${ }^{23}$ and indirect evidence i.e. the agglomeration behavior of the ultrathin Ni films. Further research is needed to provide direct evidence of such grain-to-grain texture (or lack thereof) for polycrystalline substrates.

In summary, on both $\mathrm{Ge}(100)$ and poly-Ge, agglomeration is driven by the lowering of interfacial energy. Unlike for thicker films, agglomeration in the ultrathin regime sets in at lower tempatures on polycrystalline substrate. The epitaxial texture components suppress (intrinsic) stress relaxation on $\mathrm{Ge}(100)$ and consequently delay film agglomeration.

\section{Agglomeration on a-Ge}

As was the case for the phase sequence, the nature of amorphous germanium prevents any (de)stabilizing effects of texture on the film morphology. Only disordered, high energy interfaces can be formed, which are predicted ${ }^{18}$ to be more stable against agglomeration. ${ }^{3}$ As no destabilizing axiotaxy can be formed, the films remain stable up to $440^{\circ} \mathrm{C}$, in contrast

${ }^{3}$ While the prediction of low energy interfaces agglomerating more easily holds for random or axiotaxial texture, it does not for epitaxial interfaces: such interfaces have very low energy, yet epitaxial films are known to be morphologically more stable than films with a different texture. ${ }^{27}$ However, the model does 
to those on crystalline substrates which have agglomerated significantly at this temperature.

The rapid film break-up on amorphous germanium at $440^{\circ} \mathrm{C}$ is not a result of texture, but rather a consequence of the metal-induced crystallization (MIC) of amorphous Ge. Indeed, it is well-documented ${ }^{35,36}$ that metal layers deposited on amorphous silicon and germanium significantly reduce the temperature of crystallization: a $100 \mathrm{~nm}$ amorphous Ge layer without any metal layer crystallizes only around $550^{\circ} \mathrm{C}$ under the same experimental conditions as those in Fig. 3. According to a model by Jin et al., ${ }^{37}$ silicide or germanide nodules (small, mobile grains) ${ }^{38}$ diffuse through the amorphous semiconductor, leaving polycrystalline $\mathrm{Si}$ or Ge in their wake. The atomic movement is thought to be driven by the difference in chemical potential of atoms at the nodule's interface with the polycrystalline semiconductor, and at the interface with the amorphous semiconductor. ${ }^{36,37}$ This model implies that part of the metal atoms diffuse deeper into the substrate, away from the film, as schematically shown in Fig. 10. Typically, the loss of metal atoms is negligible for thicker (e.g. $30 \mathrm{~nm} \mathrm{Ni}$ ) germanide films which remain stable during MIC. ${ }^{5}$ However, for ultrathin germanides it might comprise a major part, if not all of the film: for films grown from 2 $\mathrm{nm} \mathrm{Ni}$, all Ni atoms are found deep in the crystallized Ge layer after annealing the sample at $450^{\circ} \mathrm{C}$ and no germanide film is found at the surface (Fig. 8). The amount of atoms diffusing into the substrate is likely of the order of $10^{17} \mathrm{Ni} / \mathrm{cm}^{2}$ : even for the reaction of a $10 \mathrm{~nm} \mathrm{Ni}$ film $\left(90 \times 10^{15} \mathrm{Ni} / \mathrm{cm}^{2}\right)$, the sheet resistance increases tenfold upon crystallization (Fig. 9). Only films grown from $15 \mathrm{~nm} \mathrm{Ni}$ or more still have a continuous NiGe film at their surface after crystallization of the Ge.

It is clear that the morphological degradation mechanism for ultrathin Ni germanide films is fundamentally different on amorphous substrates than on crystalline ones: rather than the minimization of interface energy, the film's breakup is driven by the crystallization energy of amorphous Ge.

not take into account any influence of curvature on the energy of interfaces. Curving the interface of ('aligned' or 'matched') epitaxial NiGe grains would destroy the matching of planes between film and substrate. Hence, any interface roughness strongly raises the interface energy. If such an energy term is taken into account, the driving force for agglomeration in this model would diminish. 


\section{CONCLUSION}

We have shown that the reaction of Ni films with Ge is strongly influenced by thickness reduction. On crystalline substrates, low-energy epitaxial interfaces extend the temperature window in which the $\epsilon-\mathrm{Ni}_{5} \mathrm{Ge}_{3}$ phase remains present. Moreover, on single-crystalline Ge, the NiGe epitaxy delays strain relaxation for a temperature window of about $100^{\circ} \mathrm{C}$ beyond the phase's formation. The film morphology on crystalline substrates remains stable as long as the texture is (mostly) epitaxial, whereas it degrades easily once axiotaxial components can grow. On amorphous substrates, no epitaxy or axiotaxy can be established and neither effect is seen: the growth of the NiGe phase is not delayed as the film thickness goes down, and the film is more resistant against agglomeration. The amorphous nature of the substrate does have a profound effect on the film breakup: the Ni atoms diffuse into the substrate upon metal-induced crystallization, leaving no germanide film at the surface. Hence, different mechanisms of film breakup are active on crystalline and amorphous substrates. Moreover, it was shown that for the thinnest films, the largest temperature window of an unagglomerated NiGe film is achieved on amorphous Ge, which is an important result for the application of NiGe films as contact material in CMOS technology.

More generally, these results illustrate that when the film thickness is reduced, the interplay between phase formation, texture, stress and agglomeration becomes increasingly important, which can lead to different reaction paths than for thicker films. Moreover, thin film reactions which are similar on different substrates, can differ in the ultrathin regime: the precise nature of the film's interface and texture will determine which phases are stabilized, and how easily the film can agglomerate. Our results caution not to generalize the behavior of thin films $(\geq 10 \mathrm{~nm})$ to that of ultrathin films $(<10 \mathrm{~nm})$; different thin film growth mechanisms might become dominant in different thickness regimes of the same system. Due to the aggressive down-scaling trend in modern microelectronics, this is technologically relevant as well: texture, stress and agglomeration will play an increasingly important role in thin film growth for future applications. 


\section{ACKNOWLEDGMENTS}

The authors are grateful to the FWO Vlaanderen (G.0761.12N), the KU Leuven BOF (GOA/14/007) and the Bilateral Cooperation between Flanders and South Africa, and the National Research Foundation of South Africa (UID 85498) for providing financial support. We acknowledge SOLEIL for provision of synchrotron radiation facilities and we would like to thank Dr. C. Mocuta for assistance in using beamline DiffAbs. Use of the National Synchrotron Light Source, Brookhaven National Laboratory, was supported by the U.S. Department of Energy, Office of Science, Office of Basic Energy Sciences, under Contract No. DE-AC02-76CH-00016. The authors also wish to thank O. Janssens for performing the SEM measurements.

\section{REFERENCES}

${ }^{1}$ K. De Keyser, C. Van Bockstael, R. L. Van Meirhaeghe, C. Detavernier, E. Verleysen, H. Bender, W. Vandervorst, J. Jordan-Sweet, and C. Lavoie, Applied Physics Letters 96, 173503 (2010).

${ }^{2}$ E. Ma and L. H. Allen, Physical Review B 49, 13501 (1994).

${ }^{3}$ R. Pillarisetty, Nature 479, 324 (2011).

${ }^{4}$ S. Gaudet, C. Detavernier, A. J. Kellock, P. Desjardins, and C. Lavoie, Journal of Vacuum Science and technology A 24, 474 (2006).

${ }^{5}$ S. Gaudet, C. Detavernier, C. Lavoie, and P. Desjardins, Journal of Applied Physics 100, 034306 (2006).

${ }^{6}$ F. Nemouchi, D. Mangelinck, J. Lábár, M. Putero, C. Bergman, and P. Gas, Microelectronic Engineering 83, 21012106 (2006).

${ }^{7}$ C. Perrin, D. Mangelinck, F. Nemouchi, J. Lábár, C. Lavoie, C. Bergman, and P. Gas, Materials Science and Engineering B 154-155, 163 (2008).

${ }^{8}$ B. De Schutter, K. van Stiphout, N. M. Santos, E. Bladt, J. Jordan-Sweet, S. Bals, C. Lavoie, C. M. Comrie, A. Vantomme, and C. Detavernier, Journal of Applied Physics 119, 135305 (2016).

${ }^{9}$ Y. Deng, O. Nakatsuka, J. Yokoi, N. Taoka, and S. Zaima, Thin Solid Films 557, 84 (2014). 
${ }^{10}$ C. Comrie, D. Smeets, K. Pondo, C. van der Walt, J. Demeulemeester, W. Knaepen, C. Detavernier, A. Habanyama, and A. Vantomme, Thin Solid Films 526, 261 (2012).

${ }^{11}$ B. De Schutter, K. De Keyser, C. Lavoie, and C. Detavernier, Applied Physics Reviews 3, 031302 (2016).

${ }^{12}$ C. Detavernier, A. S. Özcan, J. Jordan-Sweet, E. A. Stach, J. Tersoff, F. M. Ross, and C. Lavoie, Nature 426, 641 (2003).

${ }^{13}$ F. Nemouchi, D. Mangelinck, C. Bergman, G. Clugnet, P. Gas, and J. L. Lábár, Applied Physics Letters 89, 131920 (2006).

${ }^{14}$ C. Mocuta, M.-I. Richard, J. Fouet, S. Stanescu, A. Barbier, C. Guichet, O. Thomas, S. Hustache, A. V. Zozulya, and D. Thiaudière, Journal of Applied Crystallograhy 46, $1842(2013)$.

${ }^{15}$ H. Pfisterer and K. Schubert, Zeitschrift fuer Metallkunde 41, 358 (1950).

${ }^{16}$ B. De Schutter, W. Devulder, A. Schrauwen, K. van Stiphout, T. Perkisas, S. Bals, A. Vantomme, and C. Detavernier, Microelectronic Engineering 120, 168 (2014).

${ }^{17}$ T. Grzela, G. Capellini, W. Koczorowski, M. A. Schubert, R. Czajka, N. Curson, I. Heidmann, T. Schmidt, J. Falta, and T. Schroeder, Nanotechnology 26, 385701 (2015).

${ }^{18}$ T. P. Nolan, R. Sinclair, and R. Beyers, Journal of Applied Physics 71, 720 (1992).

${ }^{19}$ U. Gösele and K. N. Tu, Journal of Applied Physics 53, 3252 (1982).

${ }^{20}$ K. De Keyser, R. L. Van Meirhaeghe, C. Detavernier, J. Jordan-Sweet, and C. Lavoie, Journal of the Electrochemical Society 157, H395 (2010).

${ }^{21}$ S. Gaudet, P. Desjardins, and C. Lavoie, Journal of Applied Physics 110, 113524 (2011).

${ }^{22}$ F. A. Geenen, W. Knaepen, K. De Keyser, K. Opsomer, R. L. Vanmeirhaeghe, J. JordanSweet, C. Lavoie, and C. Detavernier, Thin Solid Films 551, 89 (2014).

${ }^{23}$ B. De Schutter, K. De Keyser, and C. Detavernier, Thin Solid Films 599, 104 (2016).

${ }^{24}$ B. De Schutter, Phase formation and texture of thin film nickel germanides, Ph.D. thesis, UGent.

${ }^{25}$ D. J. Srolovitz and M. G. Goldiner, Journal of The Minerals, Metals and Materials Society 47, 31 (1995).

${ }^{26}$ D. Deduytsche, C. Detavernier, R. L. Van Meirhaeghe, and C. Lavoie, Journal of Applied Physics 98, 033526 (2005).

${ }^{27}$ R. T. Tung, J. M. Poate, J. C. Bean, J. M. Gibson, and D. C. Jacobson, Thin Solid Films 93, 77 (1982). 
${ }^{28}$ C. Van Bockstael, K. De Keyser, R. L. Van Meirhaeghe, C. Detavernier, J. Jordan-Sweet, and C. Lavoie, Applied Physics Letters 94, 033504 (2009).

${ }^{29}$ O. Thomas, P. Gergaud, C. Rivero, and F. M. d'Heurle, Defect and Diffusion Forum 237-240, 801 (2005).

${ }^{30}$ A. Steegen and K. Maex, Materials Science and Engineering R38, 1 (2002).

${ }^{31}$ F. A. Geenen, W. Knaepen, F. Moens, L. Brondeel, A. Leenaers, S. Van den Berghe, and C. Detavernier, Journal of Physics D: Applied Physics 49, 275307 (2016).

${ }^{32}$ S.-L. Zhang and F. M. d'Heurle, Thin Solid Films 213, 34 (1992).

${ }^{33}$ J. Tersoff and F. K. LeGoues, Physical Review Letters 72, 3570 (1994).

${ }^{34}$ K. De Keyser, C. Van Bockstael, C. Detavernier, R. L. Van Meirhaeghe, J. Jordan-Sweet, and C. Lavoie, Electrochemical and Solid-State Letters 11, H266 (2008).

${ }^{35}$ W. Knaepen, C. Detavernier, R. L. Van Meirhaeghe, J. Jordan-Sweet, and C. Lavoie, Thin Solid Films 516, 4946 (2008).

${ }^{36}$ W. Knaepen, S. Gaudet, C. Detavernier, R. L. Van Meirhaeghe, J. Jordan-Sweet, and C. Lavoie, Journal of Applied Physics 105, 083532 (2009).

${ }^{37}$ Z. Jin, G. A. Bhat, M. Yeung, H. S. Kwok, and M. Wong, Journal of Applied Physics 84, 194 (1998).

${ }^{38}$ C. Hayzelden and J. L. Batstone, Journal of Applied Physics 73, 8279 (1993).

${ }^{39}$ M. Birkholz, P. Fewster, and C. Genzel, Thin Film Analysis by X-Ray Scattering (WileyVCH Verlag GmbH and Co. KGaA, 2006). 